\title{
Roles and Responsibilities for Sustaining Open Source Platforms and Tools
}

\author{
Trevor Owens \\ U.S. IMLS \\ 1800 M St. NW \\ Washington, DC, 20036 \\ tjowens@imls.gov
}

\author{
Carl Wilson \\ Open Preservation Foundation, c/o \\ The British Library, Boston Spa, \\ Wetherby, West Yorkshire, LS23 7BQ \\ carl@openpreservation.org
}

\begin{abstract}
Developing, deploying and maintaining open source software is increasingly a core part of the core operations of cultural heritage organizations. From preservation infrastructure, to tools for acquiring digital and digitized content, to platforms that provide access, enhance content, and enable various modes for users to engage with and make use of content, much of the core work of libraries, archives and museums is entangled with software. As a result, cultural heritage organizations of all sizes are increasingly involved in roles as open source software creators, contributors, maintainers, and adopters. Participants in this workshop shared their respective perspectives on institutional roles in this emerging open source ecosystem. Through discussion, participants created drafts of a checklist for establishing FOSS projects, documentation of project sustainability techniques, a model for conceptualizing the role of open source community building activities throughout projects and an initial model for key institutional roles for projects at different levels of maturity.
\end{abstract}

\section{General Terms}

Institutional opportunities and challenges; Infrastructure opportunities and challenges;

\section{Keywords}

FOSS, Sustainability, Institutional Roles,

\section{INTRODUCTION}

As cultural heritage institutions become increasingly involved in collaborative development, deployment and maintenance of open source software an ecosystem of researchers, nonprofit organizations, cultural heritage institutions, service providers and funders have emerged to help make this work possible. The roles and responsibilities that these entities should take are often only evident in the successes of individual open source tools and platforms. Through facilitated discussion, participants in this workshop focused on formalizing the kinds of roles that these organizations can and should play in developing, deploying, sustaining, and disseminating open source software, tools, best practices, and services.

\section{PARTICIPANTS}

There were 35 participants in this day-long workshop. Attendees brought their experience working in a range of roles at a variety of

iPres 2015 conference proceedings will be made available under a Creative Commons license.

With the exception of any logos, emblems, trademarks or other nominated third-party images/text, this work is available for reuse under a Creative Commons Attribution 3.0 unported license. Authorship of this work must be attributed. View a copy of this license. institutions. There were participants from the Computer History Museum, the National Library of Sweden, the National Archives of Australia, the Bentley Historical Library, the State Archives of North Carolina, Artefactual Systems, Educopia Institute, and the John F. Kennedy Presidential Library. Participants also represented a cross section of roles (administrators, archivists, librarians, lawyers, software developers, and community managers) within organizations. This diversity of backgrounds, roles and perspectives provided invaluable input, leading to fruitful discussion.

\section{WORKING GROUP OUTCOMES}

The attendees organized themselves into four working groups. These groups began drafting guides and resources to address a range of pressing needs for improving investment and planning for FOSS digital preservation projects. The work of the groups is briefly described below.

\subsection{Checklist for Establishing FOSS Projects}

Where does one start when planning a successful open source project, or open sourcing an existing software project? While there is some work related to the maturity of FOSS projects [4] there is still a significant need for the guidance in this area. Recognizing the complexity in this space, one group began drafting a checklist for key issues to consider and explore when considering starting an open source project or shifting an existing software development project to an open source model. The group identified a range of individual issues organized into five categories; planning, legal and licensing, requirements and testing, user community, and developer community. When revised and completed, this checklist will be useful as a resource to both establish plans and also as a tool to evaluate plans for proposed tools.

\subsection{Identifying Sustainability Techniques}

Establishing approaches to address the sustainability of FOSS digital library projects remains a key issue area in the field [5]. There are various modes for generating the funds or in kind contributions necessary to make an open source software project sustainable. Through discussion of a range of individual projects and of related research this group articulated a series of techniques for sustainability and noted their strengths and weaknesses. Through this process, the group produced a set of notes highlighting key features of successful open source projects. In particular, participants noted that most mature open source projects in the digital library sector leverage core operating resources across multiple organizations. The group also noted that the most successful projects incorporate multiple streams of funding and resources helping to ensure sustainability. 


\subsection{FOSS Community Building Planning}

The success of open source software projects is anchored in their ability to engage and develop communities [1]. Through discussion of the development of successful and vital open source communities around a range of different individual projects this group began articulating critical community building activities. These activities are tied to different stages in a project (from conceptualization, to design and development, through to implementation and adoption). A key take away from the group is the importance of establishing community development plans at every stage of a project's development. There is a clear need to complete the development of this model to clarify and share which activities are appropriate at particular stages of a project.

\subsection{Organizational Roles \& Project Maturity}

This group examined and discussed different, successful open source software projects. They defined a set of project phase, identifying key roles for different institutional partners during the development of these projects. This suggested the following roles over three distinct phases of development.

Key roles identified for the initial development/ start-up phase of a product were:

- Researchers/Developers working to document needs, explore possibilities of tool creation;

- User Stakeholder groups working to develop use cases and features, as testers and as initial testers;

- a Steering Committee, made up of key individuals who can ensure institutional commitments; and

- clearly identified stakeholders working on documentation [2].

As a project reaches it's initial roll out and moves toward maturity, it becomes important to engage:

- professional associations (to get the word out about the project),

- a sustainable home (an organization focused on running and managing the project and providing services, managing membership models, and serving as a host for member driven governance).

When a product reaches maturity, it ideally will have cultivated:

- other providers (companies and or non-profits providing additional services around the product); and
- a developer community (a community of developers from multiple organizations contributing to the project.

\section{CONCLUSIONS \& NEXT STEPS}

Each group identified some next steps and key participants that plan to carry forward the work started in the meeting. This will fully realize the development of resources and guides that can be used to improve the planning, delivery and quality of open source software for digital library and digital preservation tools and systems. In closing remarks, Paul Wheatley of the Digital Preservation Coalition, stressed how critical it is for knowledge and best practice in this area to advance. Every year significant resources are invested in software development across the sector. Without further development of the kinds of resources started by these working groups, it is difficult to ensure that those investments are making the maximum impact.

\section{ACKNOWLEDGMENTS}

Many thanks to all 35 of the participants who worked in this session, as well as the iPres conference for providing a venue for this work.

\section{REFERENCES}

[1] Bacon, J. 2009. The Art of Community. O'Reilly Media.

[2] Blankenhorn, D. 2010. Why Open Source Documentation Lags. ZD Net. http://www.zdnet.com/article/why-opensource-documentation-lags/

[3] Doran, M. 2007. "The Intellectual Property Disclosure Process: Releasing Open Source Software in Academia" http://code4lib.org/2007/doran

[4] Reese, T. (2012). Purposeful Development: Being Ready When Your Project Moves From 'Hobby' to Mission Critical Issue 16, 2012-02-03 http://journal.code4lib.org/articles/6393

[5] Schaefer, S. 2010. Challenges in Sustainable Open Source: A Case Study" Issue 9, 2010-03-22 http://journal.code4lib.org/articles/2493 